\title{
Evaluación del hábitat acuático PHABSIM bi-dimensional para el establecimiento de un nuevo régimen de caudal ecológico en el río Inglares (Álava)
}

\author{
López, E..$^{1 *}$ \\ C/Cola y Goiti, $N^{o}$ 5, 5 ${ }^{\circ}$ Dch.Vitoria - Gasteiz (Álava), 01003 \\ ${ }^{1}$ Universidad de Valladolid. Graduado en Ingeniería Forestal y del Medio Natural \\ *e-mail: emiliolopezath@hotmail.com
}

\section{Resumen}

El rio Inglares situado al sur de la provincia de Álava, dentro de la Comunidad Autónoma de País Vasco (CAPV), se encuentra bajo una gran influencia antrópica debido a la creación de una minicentral hidroeléctrica que resta caudales en un tramo medio del rio. El caudal extraído directamente del cauce está destinado a la creación de energía hidroeléctrica y el regadío de viñedos y otro tipo de cultivos intensivos que se producen en rioja alavesa. Esta situación produce que el río lleve menos agua del que le corresponde al régimen natural de caudales.

El objetivo de este estudio es conocer el caudal ecológico mínimo que se debe dejar pasar a través de la minipresa situada en la parte media de la cuenca para el mantenimiento de una población saludable y estable de trucha común (Salmo trutta). Las mediciones se realizaron en un tramo de 52 metros de longitud aguas abajo de dicha derivación de caudales. Se tomaron 12 secciones transversales donde se midieron datos de velocidad del agua, calado, tipo de sustrato, además un levantamiento topográfico con puntos intermedios entre secciones.

Los resultados ponen de manifiesto que el régimen actual de caudales perjudica gravemente su hábitat (reducción de un $70 \%$ del hábitat potencial) y no se respeta su caudal ecológico mínimo. Se propone por tanto que se cumpla la distribución temporal del caudal ecológico mínimo para la trucha común asegurando así un buen estado de conservación para sus poblaciones en la parte media de la cuenca del río Inglares.

Palabras clave: derivación de caudales, estadios de desarrollo, restauración hidrológica, retención de sedimentos, ruptura de conectividad, simulación hidráulica, trucha común. 


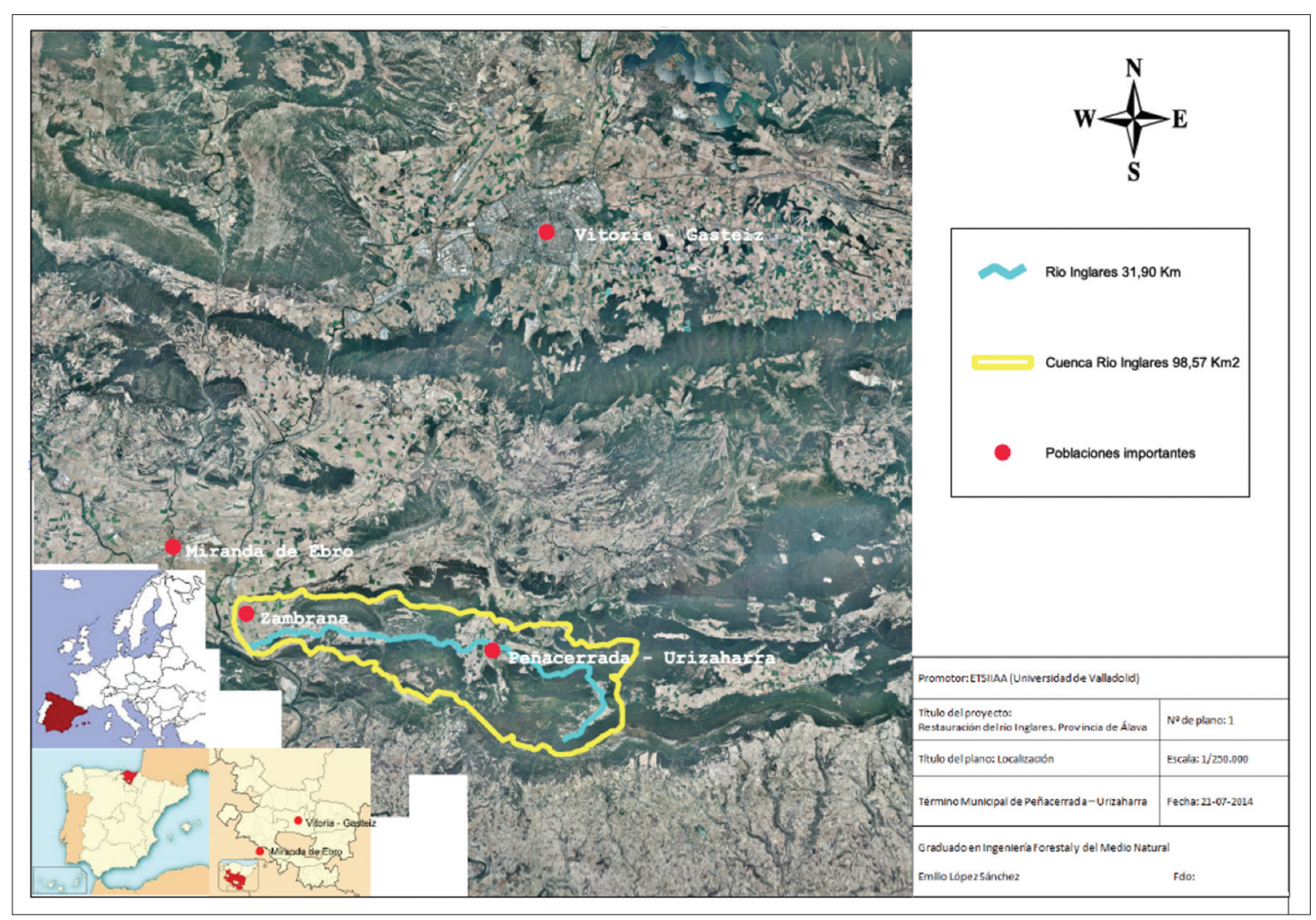

Figura 1. Localización de la cuenca del río Inglares.

\section{Introducción}

El río Inglares situado al sur de la provincia de Álava (Fig. 1) es un afluente del río Ebro de poco más de 30 kilómetros de longitud, sin embargo, está considerado como uno de los mejores para la práctica de la pesca deportiva de salmónidos en este territorio. La mayor población de trucha común (Salmo trutta) se encuentra situada en la parte media de la cuenca, donde la vegetación de ribera permanece inalterada y la conservación del bosque caducifolio adyacente así como de la ribera es excelente (Anbiotek S.L., 2012).

Sin embargo este tramo de río tiene capacidad para albergar una población más abundante y equilibrada (gran número de alevines acompañados por unos pocos ejemplares jóvenes y adultos reproductores). Este potencial no se puede desarrollar debido a que aguas arriba se encuentra situada una derivación que resta aproximadamente $2 / 3$ del caudal circulante (Fig. 2).

El agua derivada se utiliza para la generación de energía mediante una minicentral hidroeléctrica (García de Jalón, 1999). Por otra parte, el agua también se destina a regar viñedos en la Rioja Alavesa por medio de una concesión realizada a favor del ayuntamiento de Labastida.

El caudal es uno de las mayores condicionantes del hábitat físico disponible en los ríos y arroyos de pequeño tamaño. Esto de igual manera determina la biodiver- 


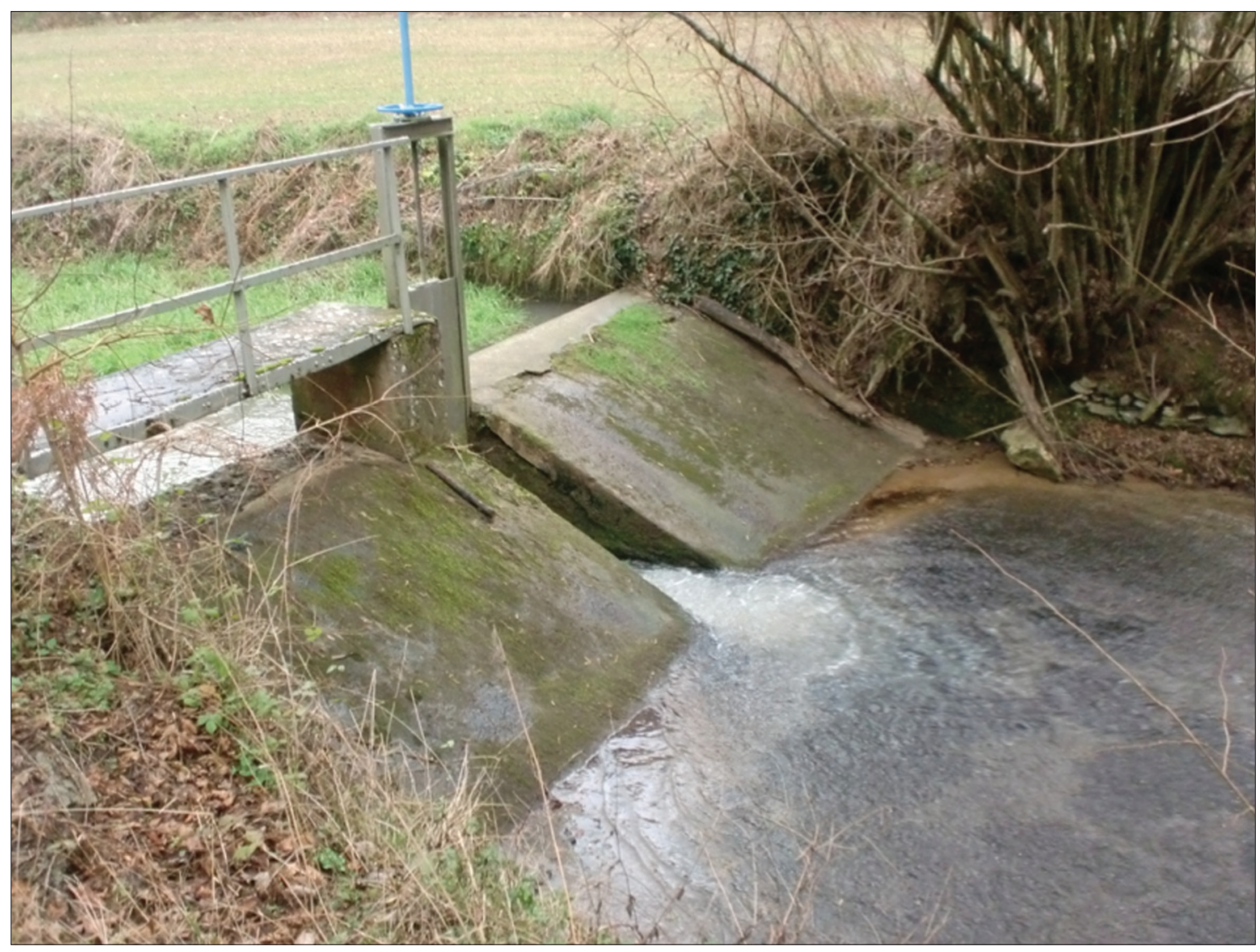

Figura 2. Vista aguas abajo de la presa y el caudal que pasa a través de ella.

sidad y el número de individuos que forman parte de las poblaciones de peces e invertebrados presentes en el ecosistema fluvial (Bunn and Arthington, 2002).

Por otra parte hay que tener en cuenta que la mayoría de especies acuáticas de la península son endemismos y están muy adaptadas a los regímenes naturales de los ríos en los que habitan. Por ejemplo, el éxito reproductor de las puestas (freza) de la trucha común (Salmo trutta) en los principales cursos fluviales de Álava se ve altamente influenciado por los caudales punta que registran en los meses posteriores a la freza (finales de invierno).

En los años con caudales excepcionalmente altos la corriente del río tiene la fuerza necesaria para llevarse la freza y esto se traduce en la pérdida de una generación en dicha población. La regulación de caudales puede minimizar o hacer eliminar este efecto negativo sobre la tasa reproductora pero por otra parte caudales excesivamente bajos y constantes generan una importante pérdida de hábitat acuático.

El resto de tramos del rio no muestran una densidad óptima de individuos de trucha común (Salmo trutta) por metro cuadrado de tramo muestreado. Dos de los tres tramos del Inglares muestreados por la empresa privada Consultora de Recursos Naturales S.L. (Vitoria - Gasteiz) en el año 2013 muestran una densidad inferior a 10 ind $\cdot \mathrm{m}^{-2}$ y el tercero una densidad de apenas 11 ind $\cdot \mathrm{m}^{-2}$. Estas densidades están catalogadas como normal - baja según el criterio utilizado por dicha empresa (Fig. 3, Tab. 1). 


\section{Densidad total de trucha}

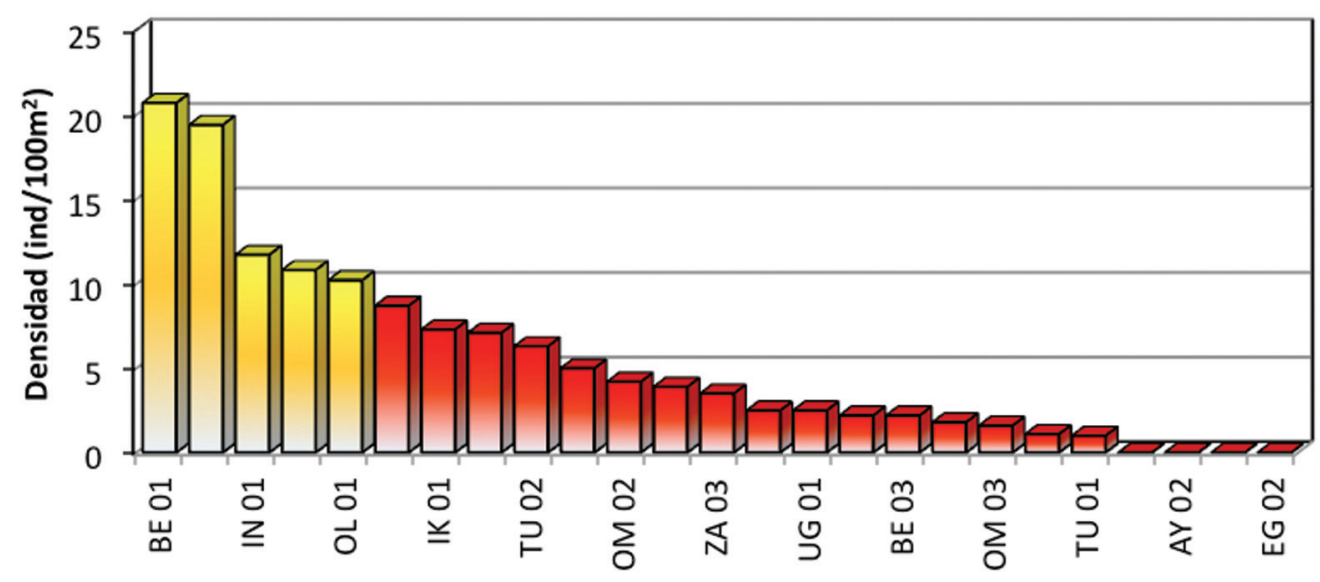

Estaciones de muestreo

Figura 3. Resultados de los muestreos realizados en el Territorio Histórico de Álava en 2013. Río Inglares (IN 01).

Tabla 1. Categoría del tramo en función de individuos por metro cuadrado.

\begin{tabular}{|c|c|c|}
\hline Calificación & Intervalo & Coloración \\
\hline Baja & $<10 \mathrm{ind} / 100 \mathrm{~m}^{2}$ & Rojo \\
\hline Normal & $10-30 \mathrm{ind} / 100 \mathrm{~m}^{2}$ & Amarillo \\
\hline Alta & $>30 \mathrm{ind} / 100 \mathrm{~m}^{2}$ & Verde \\
\hline
\end{tabular}

Debido a la importancia del tramo medio de la cuenca como proveedor de nuevos adultos reproductores, se cree conveniente realizar un estudio del caudal ecológico mínimo que se debe dejar pasar a través de la compuerta de la minipresa. Con ello se estimula la dispersión de la especie de manera natural aguas abajo de la presa, puesto que la presa carece de una escala para peces y es infranqueable.

En la base de las presas y azudes se producen zonas con alta velocidad del flujo del agua que merman la capacidad de las especies de salmónidos para franquearlas puesto que el gasto energético que debe emplear es mucho mayor que en una zona de rápidos inalterada por infraestructuras artificiales.

Aguas arriba de la presa se depositan materiales finos como pueden ser arenas y limos en consecuencia de la ralentización y estancamiento del agua. Mientras que en la zona aguas abajo del azud se produce un fenómeno de acorazamiento del lecho fluvial debido a la mayor capacidad de arrastre del agua; esto conlleva una pérdida importante de la biodiversidad de mesohábitats que afecta directamente al desarrollo de la poblaciones de trucha común (De Salinas, 2012).

Con el presente trabajo se pretende determinar cuál es el caudal ecológico mínimo que se debe dejar pasar a través de la minipresa. A su vez este caudal ecológi- 
co se calculará para los diferentes meses del año utilizando como criterio el estadio de desarrollo más restrictivo presente en dicha época del año. De esta manera se establece una distribución heterogénea de caudales a lo largo del año.

\section{Material y métodos}

El presente estudio sirve como complemento a un proyecto de restauración fluvial que se pretende llevar a cabo en la parte media - alta de la cuenca del río Inglares con el principal objetivo de mejorar las condiciones ecológicas. Dicha restauración plantea la repoblación por medio de especies autóctonas de un bosque de ribera maduro.

Aguas abajo de esta zona se encuentra la ya mencionada minipresa. Tras hacer una inspección visual de un tramo de unos 200 metros agua abajo de la minipresa se decidió realizar el estudio en un tramo de unos 50 metros de longitud situado a unos 50 metros de la detracción de caudales. Se trata de un tramo muy estrecho del río (en torno a 5-6 m). Cabe destacar que el caudal medio anual medido por la estación de aforos aguas arriba del tramo de estudio es de $3981 \cdot \mathrm{s}^{-1}\left(0,398 \mathrm{~m}^{3} \cdot \mathrm{s}^{-1}\right)$.

\subsection{Método del hábitat potencial útil (PHABSIM)}

La metodología que se va a utilizar en este estudio es conocida como Instream Flow Incremental Methodology (IFIM) y es el resultado de combinar la planificación, gestión/explotación del recurso hídrico por parte del hombre, la simulación de caudales por medio de la ingeniería hidráulica y los requerimientos ecológicos de la ictiofauna dulceacuícola representados mediante la curvas de preferencia. Teniendo en cuenta todas estas variables el método da como dato de salida una relación directa entre caudal, cantidad y calidad de hábitat potencial utilizable para una determinada especie. Esto nos permite evaluar los diferentes escenarios en función de un régimen de caudal establecido (Martínez, 2009).

Dentro de la metodología IFIM se puede dividir en 4 fases (Bovee et al., 1998):

- Identificación del problema y diagnosis: se debe tener muy en cuenta que uno de los problemas con los que nos podemos encontrar a la hora de intentar restaurar un régimen adecuado de caudales para la ictiofauna autóctona es la legislación del territorio en el que trabajemos y las diferentes instituciones que tienen competencias en materia de ríos.

- Planificación del estudio: incluye una descripción de los objetivos de las actuaciones previstas, identificación de los ecosistemas y especies acuáticas que serán objeto de estudio, delimitación del área de estudio, definición del estado actual, calibración de los modelos hidráulicos y marcarse como objetivo compatibilizar la explotación del agua como recurso con la conservación del ecosistema fluvial y las especies que lo habitan.

— Implementación: esta fase es la encargada de poner en marcha y aplicar los 
métodos y medidas necesarios para llevar a cabo el estudio del régimen de caudal ecológico mínimo para el mantenimiento de una población sana y bien estructurada (equilibrada) de trucha común (Salmo trutta).

- Análisis de alternativas y adopción de la solución definitiva: una vez finalizado el estudio existen múltiples soluciones al problema que varían en función de quien realice el estudio y de los intereses del mismo.

Desde el punto de vista de los profesionales del medio ambiente, de los organismos con competencias en materia de pesca y de los propios pescadores el objetivo es que por el río circule el régimen de caudales natural, es decir, que no hayan alteraciones a lo largo del curso de todo el río. Siguiendo esta dinámica natural del río se asegura un buen funcionamiento de los ecosistemas fluviales y el correcto desarrollo de todas las especies de fauna y flora ligadas al agua.

Para la adopción de la solución definitiva al problema hay que tener en cuenta ambos puntos de vista, además de cumplir estrictamente con la legislación vigente de la cuenca hidrográfica correspondiente. La solución definitiva marcará un caudal ecológico mínimo a respetar para cada mes del año puesto que tiene en cuenta todos los estadios de desarrollo de la especie Salmo trutta.

La metodología IFIM que se aplica en este estudio para desarrollar caudales ecológicos se desarrolla en su componente principal PHABSIM (Potencial Habitat Simulator). Este modelo, también conocido como método del hábitat potencial útil, tiene como finalidad relacionar los caudales circulantes con el hábitat físico que generan para varios estadios vitales de una o varias especies piscícolas. Esta metodología consta de tres componentes básicas: modelo de hidráulica fluvial, curvas de preferencia de la fauna y finalmente la evaluación del hábitat potencial útil.

\subsubsection{Modelo de hidráulica fluvial}

A través de la toma de datos en campo (profundidad y sustrato) se simplifica la morfología del tramo en diferentes secciones transversales. Cada una de las secciones se divide a su vez en celdas elementales de características homogéneas; en dichas subsecciones se toman datos del tipo de estrato (limo, arena, gravilla, grava, cantos, bolos, bloques o roca).

Las mediciones se llevan a cabo en un tramo representativo del hábitat que pretendemos simular (50 - 100 metros de longitud aproximadamente). Se comienza aguas abajo de la sección y poco a poco se va remontado el río. Es necesario seguir el mismo orden y metodología a la hora de tomar puntos con la estación total. Puesto que una mala planificación puede provocar errores e incongruencias a la hora de tratar los datos en gabinete.

\subsubsection{Curvas de preferencia de la fauna}

Debido a que las exigencias de hábitat de una misma especie (trucha común) varían a lo largo de su desarrollo (freza, alevín, juvenil y adulto), las curvas de prefe- 


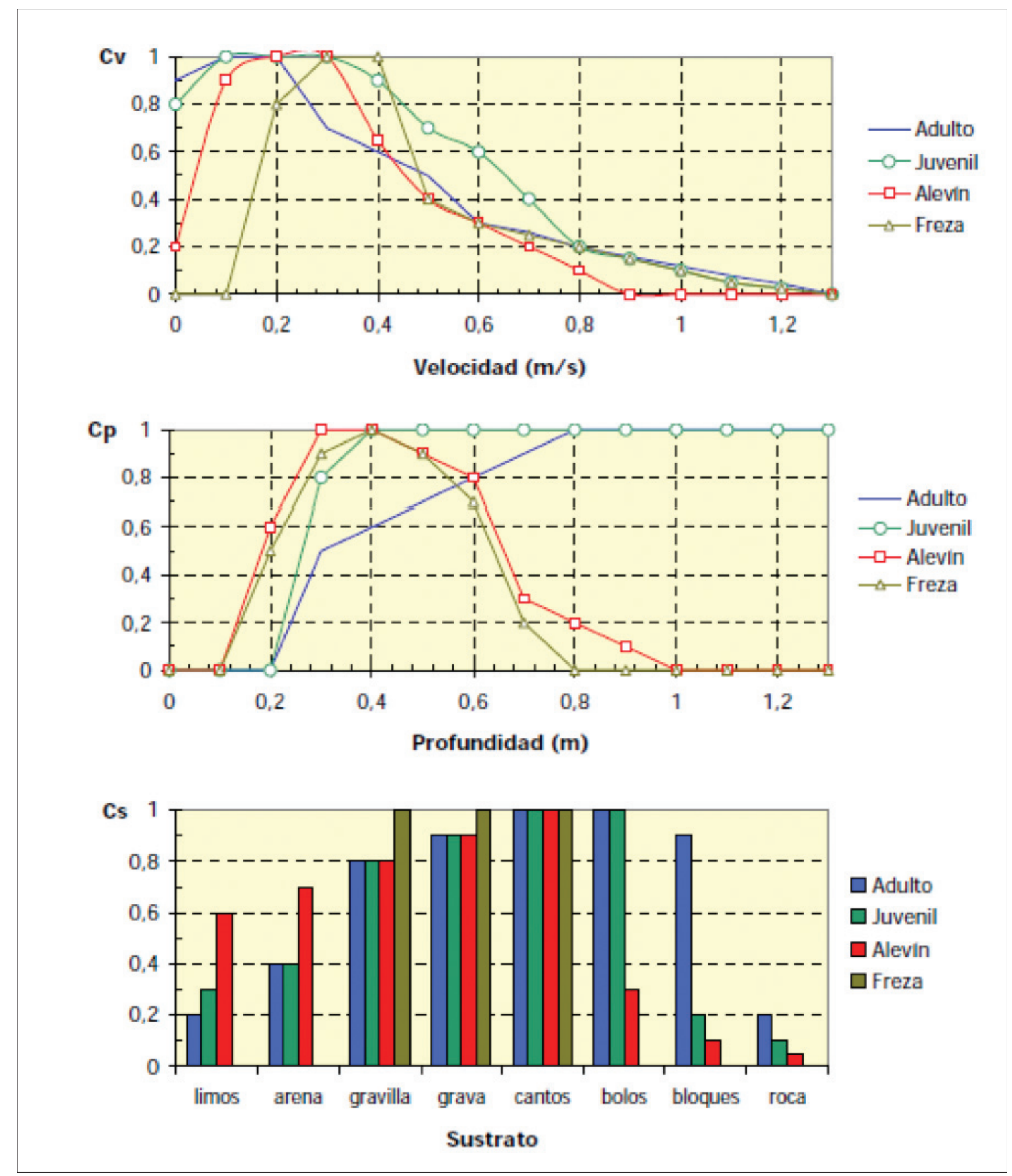

Figura 4. Curvas de preferencia de la trucha común (GARCÍA DE JALÓN, 1999).

rencia se elaboran para los distintos estadios de una especie (Fig. 4). En este caso se han utilizado las curvas de García de Jalón (García de Jalón, 1999).

\subsubsection{Evaluación del hábitat potencial útil}

Esta fase se conoce como el modelo hidrobiológico de PHABSIM. Supone la 
unión de los resultados de la simulación hidráulica con las curvas de preferencia, estableciendo una relación entre el caudal circulante y hábitat físico generado.

El objetivo final de la simulación hidrobiológica es obtener las curvas APU -caudal (Anchura Potencial Útil). Gracias a ella se propone el régimen de caudales ecológicos.

\subsection{Mediciones en campo}

Todas las mediciones se realizaron en dos días, más concretamente el día 10 y 11 de abril de 2014. Las mediciones constan de un levantamiento topográfico de las secciones, medición de la cota de la lámina de agua, velocidad del agua circulante, caracterización del sustrato del fondo y un aforo de una sección fiable.

\subsubsection{Material utilizado}

- Nivel automático Geo-Fennel No 10 x26 • Estacas de madera

- Trípode

- Mira graduada de 4 metros

- Maza y martillo

- Vara graduada

- Correntímetro Swoffer modelo 2100

- Vadeador

- Receptor GPS Garmin

- Estadillos de campo

- Cinta métrica de 50 metros

- Cámara de fotos digital

\subsubsection{Proceso operativo}

Los trabajos de campo realizados en este estudio tienen por objetivo caracterizar un tramo de 52 metros. Para ello se simplifica en secciones transversales en las que se mide la topografía del lecho, el nivel y la velocidad del agua, el tipo de sustrato y la disponibilidad de refugio.

\subsubsection{Levantamiento topográfico y del nivel de agua}

En cada sección transversal se colocan dos estacas, una en cada orilla, y se lleva la cinta métrica de una estaca a otra, situándola transversalmente al flujo de la corriente. Una vez estacionado correctamente el nivel, se procede a la medición de la sección. También se mide la topografía de la zona riparia en ambos márgenes para poder simular caudales mayores. Se toman mediciones cada 0,5 metros. Después de finalizar las mediciones en cada sección se comprueba el desnivel con respecto a la siguiente y se anota la distancia entre secciones.

\subsubsection{Velocidades}

En los mismos puntos en los que se mide la topografía de cada sección, se mide también la velocidad del agua. Dicha operación se realiza con el correntímetro, que se fija a la vara graduada y se coloca en contra corriente. 
El correntímetro se coloca a un tercio de la profundidad de agua, es decir, la distancia menos alejada del lecho del río; puesto que considera que representa la velocidad media del agua en dicho punto (Fig. 5).

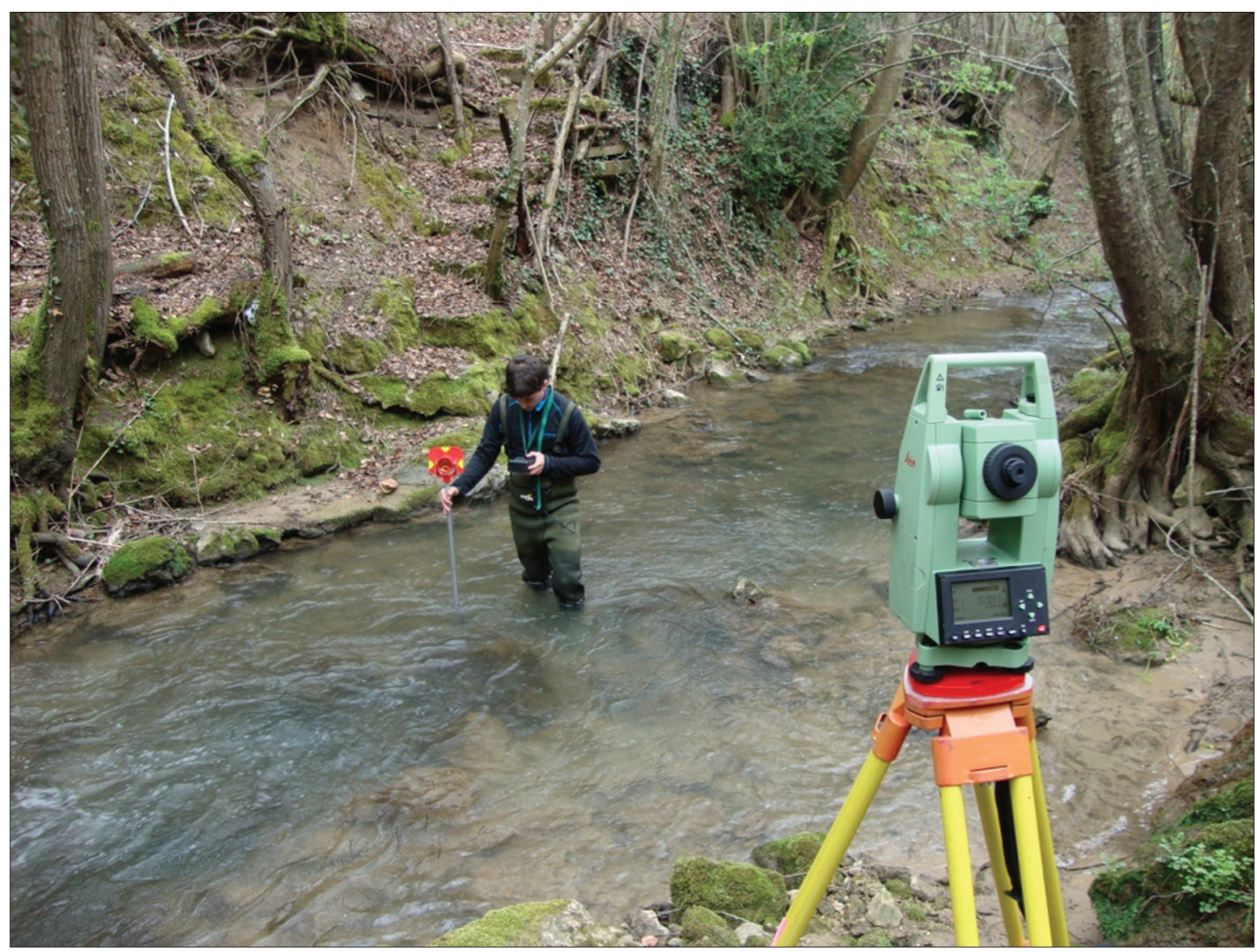

Figura 5. Medición de velocidad, tipo de sustrato y cota de la lámina de agua en uno de los puntos muestreados.

\subsubsection{Caracterización del sustrato}

Se anota el tipo de lecho de cada punto de topografía según la siguiente clasificación:
- Limo
- Cantos
- Arena
- Bolos
- Gravilla
- Bloques
- Grava
- Roca

\subsubsection{Simulación del hábitat físico}

Tras la toma de datos en campo se procede a su procesamiento informático. El programa utilizado para ello es RHASIM 3.3. Este programa permite relacionar cada caudal simulado con la superficie mojada que genera en el lecho del río. 
El siguiente paso es introducir las curvas de preferencia para cada estadio de trucha común (Salmo trutta). Por último se elaboran las curvas APU-Caudal, que relacionan los caudales circulantes simulados con el hábitat físico que generan para los diferentes estadios de desarrollo.

\section{Resultados y discusión}

\subsection{Curvas APU-Caudal}

Como resultado de la simulación hidrobiológica se obtienen estas curvas, que representan la evolución del hábitat según los caudales simulados, para cada especie y estadio simulado.

El hábitat útil del tramo puede expresarse en términos absolutos de superficie $\left(\mathrm{m}^{2}\right)$ o como porcentaje del área total del mismo (Fig. 6). La máxima superficie de hábitat disponible para todos los estadios se produce con un caudal de $0,6 \mathrm{~m}^{3} \cdot \mathrm{s}^{-1}$. A partir de dicho caudal se produce un brusco descenso a partir del cual se estabiliza.

En cuanto a la intensidad con la que las curvas ascienden, el mayor aumento de caudal se produce de $0,1 \mathrm{~m}^{3} \cdot \mathrm{s}^{-1}$ a $0,2 \mathrm{~m}^{3} \cdot \mathrm{s}^{-1}$. Posteriormente, entre los valores de 0,2 $\mathrm{m}^{3} \cdot \mathrm{s}^{-1}$ y $0,6 \mathrm{~m}^{3} \cdot \mathrm{s}^{-1}$ el hábitat aumenta pero de manera muy pausada (aumentos de caudal no suponen mayor hábitat disponible).

Entre los 0,6 y los $0,7 \mathrm{~m}^{3} \cdot \mathrm{s}^{-1}$ se produce un brusco descenso del hábitat para todos los estadios. Esto puede deberse al incremento en la velocidad del agua en el cauce que supone este aumento de caudal, haciendo el tramo menos adecuado para todos los estadios de trucha común (Salmo trutta), excepto para el adulto, posiblemente con mayor preferencia por caudales mayores. A partir de $\operatorname{los} 0,7 \mathrm{~m}^{3} \cdot \mathrm{s}^{-1}$ el hábitat disponible permanece constante a medida que crecen los caudales.

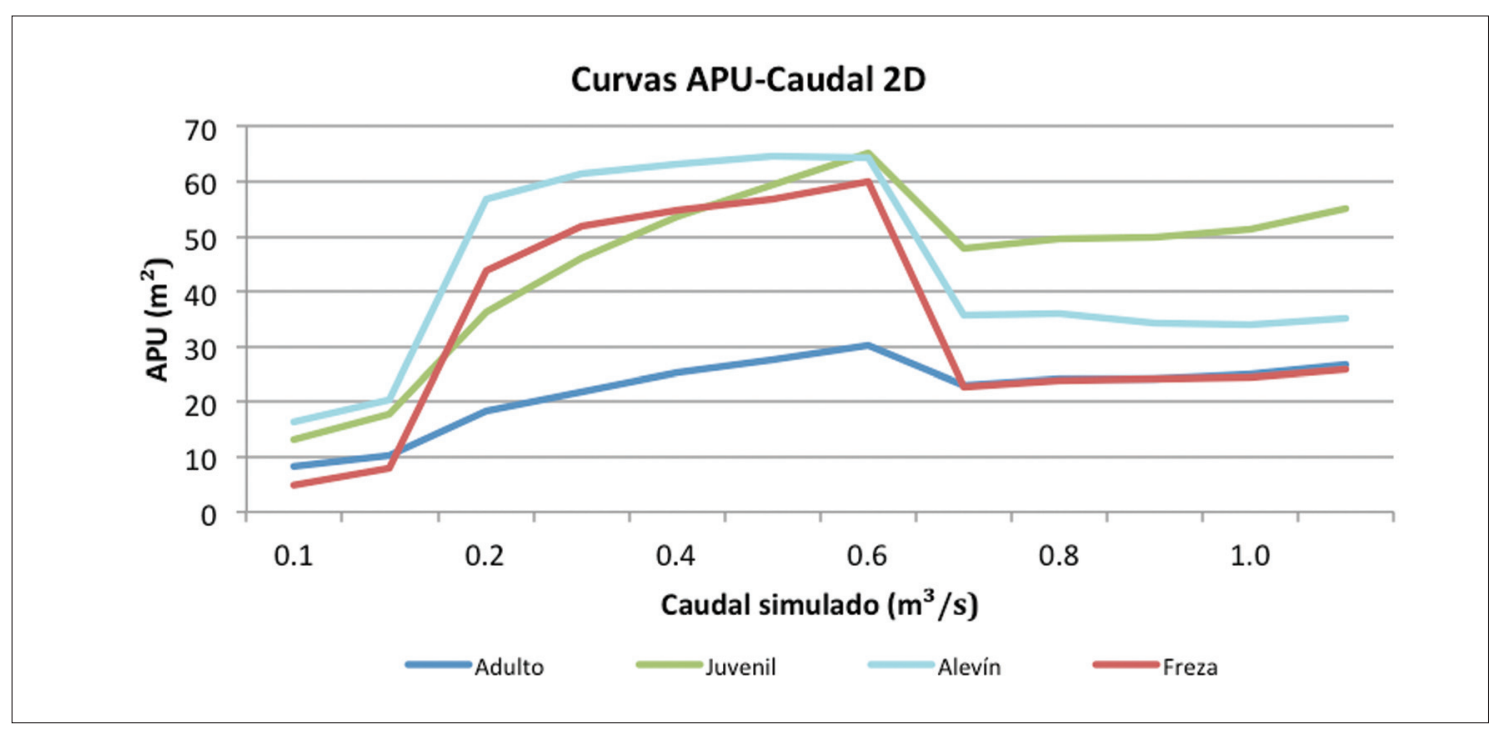

Figura 6. Curva APU-Caudal expresado en metros cuadrados para los diferentes estadios de trucha común. 


\subsection{Análisis comparativo del hábitat en el régimen natural y alterado}

El analisis espacial del hábitat da como resultado las curvas APU-Caudal, a partir de las cuales puede establecerse el régimen de caudales ecológicos. El analisis temporal permite comparar las distintas alternativas propuestas con la situación inicial, evaluando el impacto de cada una a lo largo del tiempo.

En este estudio se compara el hábitat que genera para la trucha común (Salmo trutta) el régimen natural de caudales y el régimen alterado provocado por la derivación de agua de la minicentral.

Basándose en los datos de la estación de aforo se deducen los caudales para el régimen natural y el régimen alterado (extracción de un $66 \%$ del caudal natural) en los doce meses del año (Tab. 2).

Tabla 2. Caudales medios mensuales en el régimen natural y alterado.

\begin{tabular}{|c|c|c|}
\hline Mes & Régimen natural (l/s) & Régimen alterado (l/s) \\
\hline octubre & 252 & 76 \\
\hline noviembre & 268 & 80 \\
\hline diciembre & 315 & 95 \\
\hline enero & 376 & 113 \\
\hline febrero & 490 & 147 \\
\hline marzo & 561 & 168 \\
\hline abril & 532 & 160 \\
\hline mayo & 534 & 160 \\
\hline junio & 514 & 154 \\
\hline julio & 354 & 106 \\
\hline agosto & 308 & 92 \\
\hline septiembre & 277 & 83 \\
\hline
\end{tabular}

Estos datos se han procesado con el módulo TIMESER de RHABSIM, que permite evaluar la efectividad de cada alternativa mediante series temporales de hábitat y los histogramas de APU acumulada. Las series temporales de hábitat (STH) representan la evolución del APU a lo largo del año para cada especie y estadio considerado, bajo una alternativa o régimen de caudales (Fig. 7, Fig. 8).

En el análisis de la serie temporal de hábitat para cada uno de los estadios apreciamos claramente que la derivación de caudal para producción de energía eléctrica provoca la pérdida de una gran área habitable a lo largo de todo el año. La freza es sin duda el estadio más perjudicado, que en noviembre se queda prácticamente sin hábitat en este tramo aguas abajo de la derivación (Fig. 9).

Esta gráfica ilustra claramente que la detracción de caudales de la minipresa resta zonas habitables a la trucha común (Salmo trutta) en todas sus fases de desarrollo. La disminución del hábitat varia entre el $50 \%$ y el $90 \%$, para alevín y freza respectivamente. 


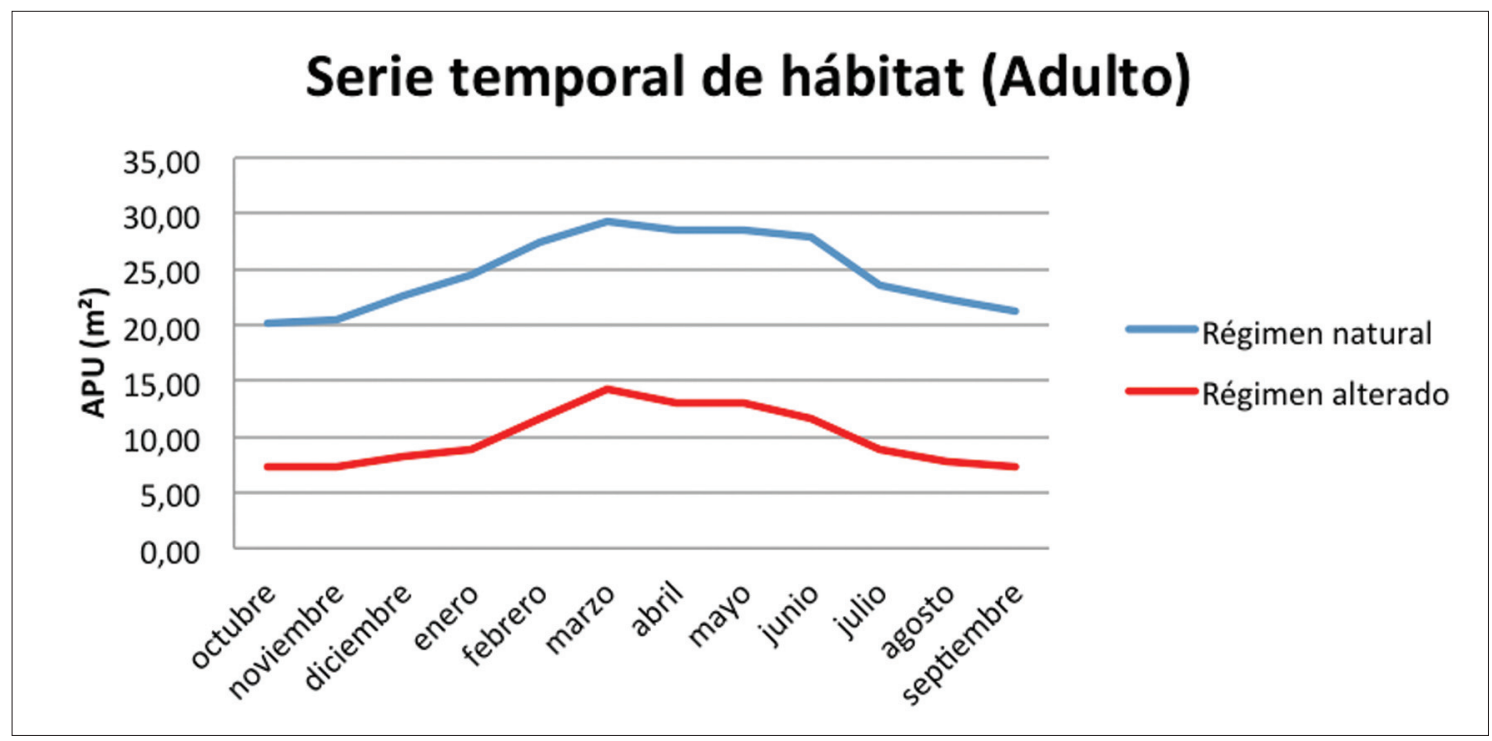

Figura 7. Evolución mensual del APU para la trucha adulta en régimen natural / régimen alterado.

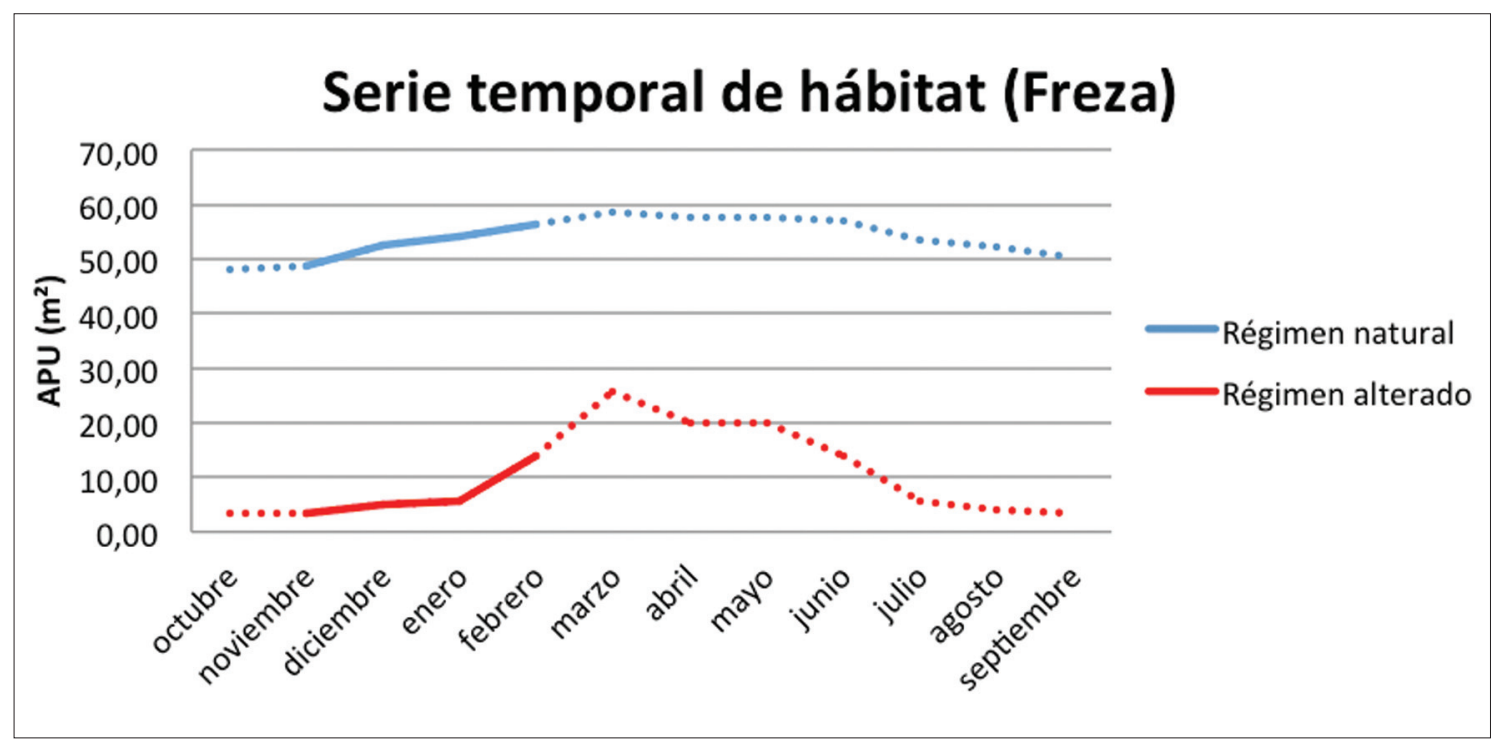

Figura 8. Evolución mensual del APU para la freza de la trucha en régimen natural / régimen alterado.

\subsection{Régimen de caudales ecológicos}

El caudal ecológico mínimo para cada uno de los estadios se determina a partir de las curvas APU-Caudal mostradas en el punto anterior. Se determina que el caudal ecológico mínimo para un estadio en concreto es el que deja un $50 \%$ del WUA máximo.

Todos los estadios de la trucha común no están presentes durante todo el año, por lo que el caudal ecológico mínimo debe varíar con los meses. La siguiente tabla (Tab. 4) muestra que estadios están presentes en cada mes del año. 
Tabla 3. Caudal ecológico para la trucha común (Salmo trutta) en sus diferentes estadios de desarrollo.

\begin{tabular}{|c|c|}
\hline Estadio & Caudal Ecológico $\left(\mathbf{m}^{\mathbf{3}} \cdot \mathbf{s}^{-1}\right)$ \\
\hline Adulto & 0,17 \\
\hline Juvenil & 0,17 \\
\hline Alevín & 0,18 \\
\hline Freza & 0,21 \\
\hline
\end{tabular}

Tabla 4. Distribución temporal de la presencia de los diferentes estadios de trucha común (Salmo trutta).

\begin{tabular}{|c|c|c|c|c|c|c|c|c|c|c|c|c|c|}
\hline Estación & \multicolumn{3}{|c|}{ Otoño } & \multicolumn{3}{c|}{ Invierno } & \multicolumn{3}{c|}{ Primavera } & \multicolumn{3}{c|}{ Verano } \\
\hline Estadio/Mes & sep & oct & nov & dic & ene & feb & abr & mar & may & jun & jul & ago \\
\hline Alevín & & & & & & X & X & X & X & & & \\
\hline Juvenil & & & & & & & & X & X & X & X & X \\
\hline Adulto & $\mathrm{X}$ & $\mathrm{X}$ & $\mathrm{X}$ & $\mathrm{X}$ & $\mathrm{X}$ & $\mathrm{X}$ & $\mathrm{X}$ & $\mathrm{X}$ & $\mathrm{X}$ & $\mathrm{X}$ & $\mathrm{X}$ & $\mathrm{X}$ \\
\hline Freza & & & $\mathrm{X}$ & $\mathrm{X}$ & $\mathrm{X}$ & $\mathrm{X}$ & & & & & & \\
\hline
\end{tabular}

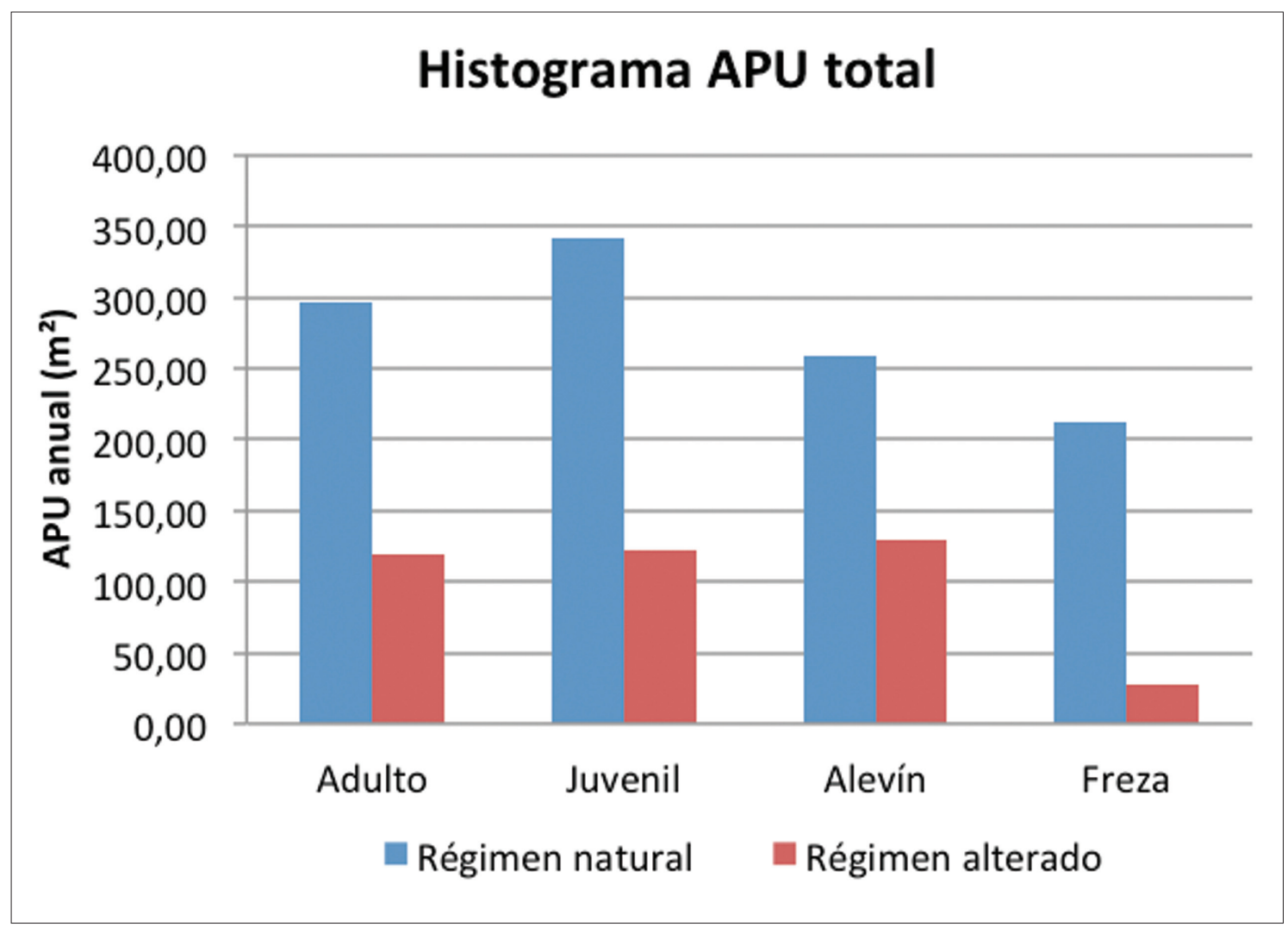

Figura 9. APU anual acumulado para los diferentes estadios de la trucha común en el régimen natural y el régimen alterado. 


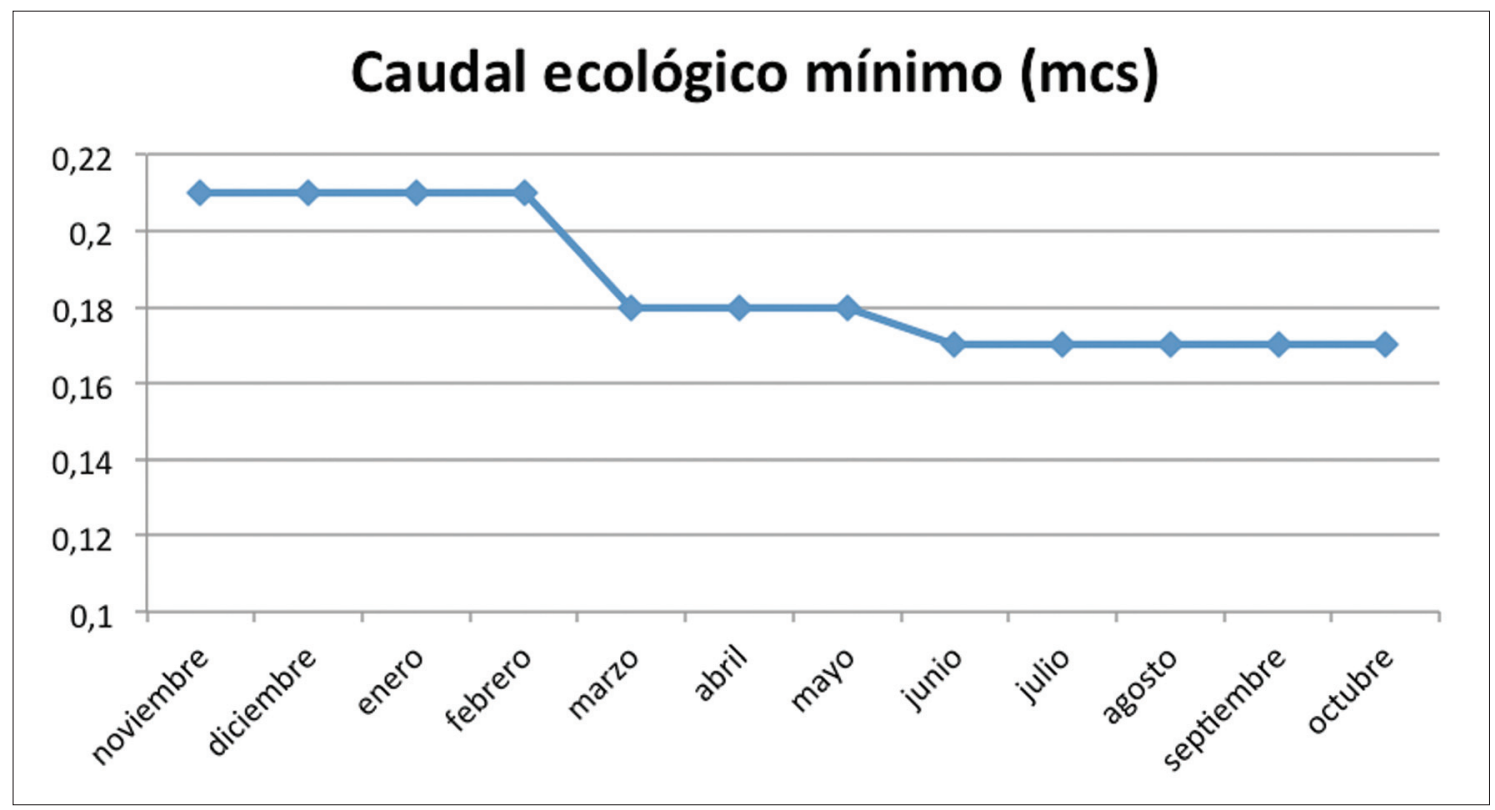

Figura 10. Distribución temporal del caudal ecológico mínimo para la trucha común (Salmo trutta).

De esta forma se puede determinar un caudal ecológico mínimo para cada mes del año; atendiendo al estadio más restrictivo (caudal ecológico más alto) presente en cada mes (Fig. 10).

Comparando los caudales ecológicos mínimos y los caudales alterados aguas abajo de la derivación se comprueba que no respetan en ninguna época el año, siendo la freza el estadio más perjudicado puesto que posee el caudal ecológico mínimo más alto.

\subsection{Discusión}

Cuando el curso del agua se encuentra con una barrera impermeable (no dejan pasar un gran flujo de agua a través de ella a diferencia por ejemplo, de los deflectores vivos) el flujo se lamina y la velocidad del agua se ralentiza notablemente. En consecuencia todos los sedimentos que transporta el río, el caudal sólido (Ollero et al., 2011), se depositan aguas arriba de la presa y esto la parte situada aguas abajo deja de recibir aportes de materiales de granulometría gruesa - media, nutrientes y materia orgánica (Brandt, 2000).

En contraposición, el lecho del río aguas arriba de la presa se colmata y taponando los frezaderos y refugios naturales de las orillas (huecos formados de manera natural por piedras y conjunto de raíces).

Antes de conocer los resultados del estudio del caudal ecológico por medio de la metodología IFIM para evaluar el hábitat potencial útil se esperaba que la freza fuera el estadio de desarrollo más afectado. Efectivamente los datos (Fig. 9) así lo han confirmado, suponiendo la pérdida de hasta un $90 \%$ del hábitat potencial útil. Este dato es alarmante porque se trata del estadio que se encarga de asegurar las futuras generaciones de Salmo trutta. 
No se esperaba que los estadios más desarrollados (alevín, juvenil y adulto) sufrieran una pérdida tan grande de hábitat ya que son menos exigentes en cuanto a tipo de sustrato, velocidad del agua y cota de la lámina de agua. Sin embargo los resultados nos revelan que el alevín, el juvenil y el adulto han perdido el 50\%, 65\% y 60\% del hábitat respectivamente.

A modo de conclusión, los resultados obtenidos certifican que el actual dique construido para derivar gran parte del caudal circulante (se estima que dos terceras partes) supone una gran pérdida del hábitat potencial para la única especie de salmónido que vive en el Inglares (Museo Nacional de Ciencias Naturales, 2001).

También queda de manifiesto que la actual gestión los ríos de la Comunidad Autónoma Vasca y establecimiento de los caudales ecológicos mínimos para los mismos no tiene en cuenta la estacionalidad de los caudales ni los diferentes requerimientos de los estadios de desarrollo de la trucha común (Salmo trutta). Sin embargo, tal y como se ha comentado al principio de este trabajo, el tiempo, los conocimientos y el material necesario para llevar a cabo este tipo de cálculos hace inabarcable dicha tarea.

\section{Conclusiones}

Mediante este estudio, se demuestra a través de una metodología contrastada a nivel internacional que la presa instalada en el río Inglares tiene un efecto negativo en el ecosistema fluvial. Los efectos se producen por dos principales causas. La presa sirve para restar gran parte del caudal del Inglares e impide la conectividad entre la parte media y alta de la cuenca. Esto es de gran relevancia puesto que limita totalmente la dispersión de manera natural aguas arriba de especies autóctonas tanto de ciprínidos como de salmónidos (exclusivamente trucha común).

\section{Bibliografía}

Anbiotek S.L. (2012). Red de seguimiento del estado biológico de los ríos de la comunidad autónoma del país vasco (informe de resultados. campaña 2011). URA (Agencia Vasca del Agua). Bilbao.

Bovee, K. D., Lamb, B. L., Bartholow, J. M., Stalnaker, C. B., \& Taylor, J. (1998). Stream habitat analysis using the instream flow incremental methodology. Geological survey and biological resources division. Springfield, Virginia, Estados Unidos.

Brandt, S. A. (2000). Classification of geomorphological effects downstream of dams. Institute of Geography, University of Copenhagen. Copenhagen, Dinamarca.

Bunn, S. E., \& Arthington, A. H. (2002). Basic principles and ecological consequences of altered flow regimes for aquatic biodiversity. Faculty of Environmental Sciences Griffith University Nathan. Queensland, Australia.

De Salinas, P. (2012). Análisis del uso, la eficiencia y la necesidad del paso para peces en el azud de salinas (Río Cinca, Huesca). Endesa (Dirección de Medio Ambiente y Desar- 
rollo Sostenible Subdirección de Medio Ambiente España y Portugal, y Cambio Climático).

García de Jalón, D. (1999). Manual Práctico sobre minicentrales hidroeléctricas. AEMS (Asociación Española para la mejora de los salmónidos).

Intecsa-Inarsa S.A. (2003). Estudio de Evaluación de los Recursos Hídricos Totales en el Ámbito de la CAPV. Departamento de Ordenación del Territorio y Medio Ambiente (Dirección de Aguas) del Gobierno Vasco.

Martínez Austria, P. F. (2009). Determinación del hábitat potencialmente utilizable por la especie Salmo trutta en un tramo del río Lozoya, España. Instituto Mexicano de Tecnología del Agua. Jiutepec, Morelos, México.

Museo Nacional de Ciencias Naturales. (2001). Atlas y Libro Rojo de los Peces Continentales de España. ELECE Industria Gráfica S.L. Madrid.

Ollero, A., Ibisate, A., Acín, V., Díaz, E., Granado, D., \& Horacio, J. (2011). Innovación y libertad fluvial. VI Congreso Ibérico sobre Gestión y Planificación del Agua. Fundación Nueva Cultura del Agua, Talavera de la Reina, Toledo. 